\title{
Axial R
}

National Cancer Institute

\section{Source}

National Cancer Institute. Axial R. NCI Thesaurus. Code C103220.

Chirality axis based stereochemistry where, using the Cahn-Ingold-Prelog (CIP) priority rules, the priorities (from highest to lowest) of the substituent atoms exist in a clockwise direction. 